\title{
Interleukin-17 regulation: an attractive therapeutic approach for asthma
}

\author{
Seoung Ju Park and Yong Chul Lee*
}

\begin{abstract}
Interleukin (IL)-17 is recognized to play a critical role in numerous immune and inflammatory responses by regulating the expression of various inflammatory mediators, which include cytokines, chemokines, and adhesion molecules. There is growing evidence that IL-17 is involved in the pathogenesis of asthma. IL-17 orchestrates the neutrophilic influx into the airways and also enhances T-helper 2 (Th2) cell-mediated eosinophilic airway inflammation in asthma. Recent studies have demonstrated that not only inhibitor of IL-17 per se but also diverse regulators of IL-17 expression reduce antigen-induced airway inflammation, bronchial hyperresponsiveness, and Th2 cytokine levels in animal models of asthma. This review will summarize the role of IL-17 in the context of allergic airway inflammation and discuss the therapeutic potential of various strategies targeting IL-17 for asthma.
\end{abstract}

\section{Introduction}

Asthma is a common airway disorder that is characterized by chronic airway inflammation, mucus production, and airway hyperresponsiveness (AHR) with airway remodeling. Airway inflammation in asthma usually involves polarization of the $\mathrm{T}$ lymphocyte response to $\mathrm{T}$ helper 2 (Th2) cells [1]. The pathologic role of Th2 cells is mediated through the release of Th2 cytokines that are essential for immunoglobulin E (IgE) synthesis, chemokine production, airway eosinophilia, smooth muscle hyperplasia, mucus production, and AHR [2-4]. As Th1 cells secrete interferon (IFN)- $\gamma$ that inhibits the proliferation of Th2 cells, Th1 cells have been suggested to display a regulatory function in allergic asthma [4]. Thus, the concept of Th1/Th2 paradigm has been of vital interest to grasp the molecular and cellular mechanism and discover therapeutic modalities in asthma. Recently, a third subset of effector helper T cells that exhibit functions distinct from Th1 and Th2 cells and preferentially produce interleukin (IL)-17 (named Th17 cells) has been discovered, updating the Th1/Th2 paradigm [5-7]. On allergen sensitization, Th17 cells home to the lung and enhance not only neutrophilic airway inflammation but also Th2 cell-mediated eosinophilic airway inflammation in mouse models of asthma [8,9]. These observations

\footnotetext{
* Correspondence: leeyc@jbnu.ac.kr

1 Department of Internal Medicine and Research Center for Pulmonary Disorders, Chonbuk National University Medical School, Jeonju, South Korea Full list of author information is available at the end of the article
}

have indicated that investigation of the differentiation, effector function, and regulation of Th17 cells may offer a new way to control asthma.

The IL-17 family consists of six members including IL17 (now synonymous with IL-17A), IL-17B, IL-17C, IL17D, IL-17E (also called IL-25), and IL-17F [10]. IL-17, the most investigated member in this family, exerts a wide variety of biological activities due to ubiquitous distribution of its receptor [10]. IL-17 is implicated in numerous immune and inflammatory responses primarily as a pro-inflammatory regulator by inducing the expression of various inflammatory mediators, such as cytokines, chemokines, adhesion molecules, and growth factors [6,11-13]. There is emerging evidence that an increase in IL-17 level is closely associated with a range of inflammatory diseases including rheumatoid arthritis, multiple sclerosis, inflammatory bowel diseases, and psoriasis $[14,15]$. In asthmatic patients, IL-17 expression has been shown to increase in sputum, lung cells, bronchoalveolar lavage (BAL) fluids, and peripheral blood [16-21]. Evidence for the involvement of IL-17 in the pathogenesis of asthma is further provided by the finding that expression of IL-17 mRNA is up-regulated in the airways of a mouse model of asthma [18]. Therefore, IL-17 has been suggested as a crucial regulator of allergic asthma. In this review, we focus primarily on the regulatory pathways and roles of IL-17 in airway inflammation and scrutinize the therapeutic potential of various strategies targeting IL-17 for asthma. 


\section{IL-17: sources and regulation of production}

IL-17 was identified as a rodent complementary DNA transcript named cytotoxic T-lymphocyte-associated antigen 8 (CTLA-8) in 1993 [19]. Originally, CTLA-8 was not recognized as a cytokine due to its unusual amino acid sequence. However, subsequent characterization revealed that this molecule is produced by $\mathrm{T}$ cells and thus renamed as IL-17 [20,21]. Genomic sequencing led to the discovery of five additional family members designated IL-17B, IL-17C, IL-17D, IL-17E, and IL-17F [10]. Even though the cellular sources and expression patterns of the mammalian IL-17 family members are different, they all exert pro-inflammatory activity [22]. Among the IL-17 family members, the most investigated cytokine is IL-17. IL-17 is a disulfide-linked homodimeric glycoprotein consisting of 155 amino acids with a molecular weight of $35 \mathrm{kDa}[20,23]$. It has been known that IL-17 is produced predominantly by a specific subset of Th cells, namely Th17 cells [5]. Additionally, other cell types such as CD8 ${ }^{+} \mathrm{T}$ cells, $\gamma \delta \mathrm{T}$ cells, and natural killer T cells also produce IL-17 [14,24,25]. Eosinophils, neutrophils, macrophages, and monocytes can also be sources of IL-17 in some cases $[7,16,23]$.

The differentiation of Th17 cells from naïve $\mathrm{T}$ cells depends on the combination of IL-6 plus transforming growth factor (TGF)- $\beta[26,27]$. In the presence of IL-6 and TGF- $\beta$, a specific Th17 cell transcription factor, retinoic acid receptor-related orphan receptor (ROR)- $\gamma \mathrm{t}$ is up-regulated [28]. While IFN- $\gamma$ and IL-4 produced by Th1 and Th2 cells, respectively, are able to reinforce the differentiation to polarized $\mathrm{T}$ cell subtype acting as an autocrine factor, IL-17 does not enforce the differentiation of Th17 cells [26]. Instead, IL-21 produced by Th17 cells acts in a positive feedback loop to differentiate Th17 cells [29]. IL-23 expands and stabilizes Th17 cells to produce IL-17, IL-17F, IL-21, and IL-22 [30,31]. In addition, signal transducer and activator of transcription 3 (STAT3) appears to be the essential signaling molecule for the differentiation of Th17 cells because IL-21 is induced in a STAT3-dependent manner [32,33]. Recent studies with both human and mouse have demonstrated that IL-1 $\beta$ is essential in the early differentiation of Th17 cells and conversion of Foxp $3^{+} \mathrm{T}$ cells into IL-17-producing cells $[34,35]$. IL-1 $\beta$ synergizes with IL-23 and IL-6 to regulate Th17 cell differentiation and to maintain cytokine expression in effector Th17 cells [34]. Altogether, there is a variety of molecules regulating the differentiation or stabilization of Th17 cells, and they can be attractive targets for blocking IL-17 generation.

\section{IL-17: signaling pathway and biological roles}

A first receptor for IL-17, IL-17R (renamed IL-17RA), was described with the discovery of IL-17 [19,20]. Similar to the IL-17 cytokine family, IL-17 receptors form a unique family composed of five members which are IL17RA, IL-17RB, IL-17RC, IL-17RD, and IL-17RE [22]. Among these IL-17 receptors, IL-17RA is the cognate receptor for IL-17, and human IL-17RC also binds IL-17 in spite of its higher affinity for human IL-17F [36]. Toy et $a l$ have demonstrated that the biological activity of IL-17 is dependent on a formation of receptor complex composed of IL-17RA and IL-17RC, providing a potential framework for elucidating the interactions between the expanded family of IL-17 ligands and their receptors [37]. Nevertheless, many questions about IL-17 ligand-receptor relationships and IL-17 receptor signaling pathway are unanswered.

After activation of the IL-17RA by the binding of IL-17, IL-17 signaling has been shown to induce various downstream pathways which will be described below. IL-17 activates nuclear factor- $\mathrm{kB}(\mathrm{NF}-\mathrm{kB})$ and mitogen-activated protein kinase (MAPK) pathways [38,39]. Schwander et al have found that tumor necrosis factor receptorassociated factor 6 is important for IL-17-induced NF- $\mathrm{KB}$ activation and the expression of IL- 6 or intercellular adhesion molecule (ICAM)-1 [40]. Recent studies have shown that the adaptor protein NF- $\mathrm{kB}$ activator 1 (Act-1) plays an essential role in IL-17-dependent signaling [4143]. The expression of inflammation-related genes induced by IL-17 is abolished in Act1-deficient cells $[41,42]$. However, an Act-1-independent signaling event such as activation of Janus kinase (JAK)1-associated phosphoinositide 3-kinase (PI3K) is described [44], and so the IL-17 signaling cascade is far from being completely defined.

IL-17 is known to induce the secretion of IL-6, CXCL8 (IL-8), granulocyte colony-stimulating factor (G-CSF), and prostaglandin E2 from normal synoviocytes and other adherent cells of various human tissues such as kidney epithelial cells, skin fibroblasts, brain endothelial cells, lung fibroblasts, and bronchial epithelial cells, thus indicating its link to inflammatory reaction [20,45]. When cultured in the presence of IL-17, fibroblasts sustained the proliferation of $\mathrm{CD} 34^{+}$hematopoietic progenitors and their preferential maturation into neutrophils [45]. These results have suggested a potential contribution of IL-17 to neutrophil biology. Furthermore, a major group of $\mathrm{IL}-17$ target genes is neutrophil-attracting chemokines, which include CXCL1 (Gro- $\alpha$ ), CXCL2 (Gro- $\beta$ ), CXCL5, CXCL6 (GCP-2), CXCL8, and CCL2 (MCP-1) $[45,46]$. Therefore, the key biological function of IL-17 is associated with neutrophil-dominated inflammation, as a promoter of granulopoiesis, neutrophil accumulation, and neutrophil activation. In addition, IL-17 induces the expression of not only eosinophil-guiding chemokines like CCL5 (RANTES) and CCL11 (eotaxin) but also other inflammatory mediators like ICAM-1 and cyclooxygenase-2 [40,46-48]. A more recent study by Hsu 
et al has shown that blocking IL-17 signaling disrupts $\mathrm{CD}^{+} \mathrm{T}$ cell and $\mathrm{B}$ cell interactions required for the formation of germinal centers and reduces humoral responses, indicating the significant impact of IL-17 on immune response [49]. Taken together, IL-17 acts as an orchestrating cytokine in immune and inflammatory responses.

\section{IL-17 in asthma}

Since the discovery of IL-17 and its key property as a proinflammatory cytokine, IL-17 has been found to be closely associated with a range of inflammatory diseases, including rheumatoid arthritis, multiple sclerosis, inflammatory bowel diseases, and psoriatic disease $[14,15]$. Bronchial asthma is one of the IL-17-related diseases which have been studied actively.

\section{1) Involvement of IL-17 in asthma: clinical evidence}

IL-17 is up-regulated in lung tissues, BAL fluids, sputum, and peripheral blood from patients with allergic asthma $[16,17,50-55]$. In the sputum of asthmatic patients, the increased levels of IL-17 mRNA expression correlate with the number of neutrophils [52]. Thus, IL-17 seems to contribute to neutrophilic accumulation in asthma, in accordance with the well-known biological function of IL-17 promoting neutrophil-dominated inflammation [51]. Although it has been well established that the pathognomonic features of asthma are mediated by eosinophils, mast cells, and Th2 cells [1], the number of neutrophils is increased in the airways of severe asthma [56]. Therefore, IL-17, whose signaling induces neutrophil recruitment into the airways, can be an important cytokine in the pathogenesis of asthma and the determination of the disease severity. Actually, the percentages of Th17 cells as well as the levels of IL-17 in airway and plasma tend to increase with the disease severity in asthmatic patients $[17,55]$. Somewhat surprisingly, the IL-17 mRNA levels correlate positively with the IL-5 mRNA levels in sputum from asthmatic patients [52]. These data may provide a potential clue regarding the association of IL-17 with Th2-mediated eosinophilic airway inflammation in asthma. Both in plasma and in activated peripheral blood mononuclear cells from allergic asthmatics, the increase in IL-17 concentration is accompanied by the enhanced concentration of IL-23 which is a critical regulator of IL-17 [55]. In addition, an increase in transcription factor RORyt level is found in allergic asthmatics [55]. These findings indicate that increased expression of IL-23 and RORyt may contribute to the increase in IL17 expression in asthmatic patients. Therefore, the results in asthmatic patients suggest that besides predominant Th2 immunity, abnormal Th17 immunity is also involved in the pathogenesis of allergic asthma.

\section{2) Involvement of IL-17 in asthma: animal models and in vitro studies}

In a murine model of allergen-induced airway inflammation, epicutaneous sensitization and subsequent inhalation challenge of ovalbumin (OVA) resulted in an increase in IL-17 expression of the lung, whereas intraperitoneal sensitization did not induce IL-17 response [57]. On the other hand, pulmonary IL-17 was induced in the mice sensitized subcutaneously with OVA [58]. Wilson et al have demonstrated that lipopolysaccharide (LPS) sensitization via the airway promotes strong Th17 responses with modest Th2 responses, while sensitization through the peritoneum primes strong Th2 responses [9]. In addition, after intranasal sensitization into the mice with a clinically relevant aeroallergen, house dust mite (HDM), IL-17 is produced in an antigen-specific manner $[59,60]$. These data have suggested that the method of sensitization or type of antigen may affect IL-17 response in murine model of allergic airway inflammation. Even so, most of previous studies using mouse models of asthma have shown that IL-17 expression in the airways is upregulated after sensitization and challenge with the antigen, agreeing with the human data [11,13,61]. All of these observations suggest that IL-17 is involved in the pathogenesis of allergic asthma.

As research on the role of IL-17 in allergic airway inflammation is still in an early stage, there is limited literature addressing the regulation of IL-17 and its related molecules in asthma. The main source of IL-17, Th17 cells have been suggested to migrate into the asthmatic airway following antigen challenge in mouse models of asthma $[4,9,62]$. In addition, natural killer $\mathrm{T}$ cells and $\gamma \delta$ T cells, which produce IL-17 in the lung, contribute to the asthmatic responses through secretion of Th2 cytokines $[9,62,63]$. Alveolar macrophages also produce IL-17 and promote asthmatic development in OVA-inhaled mice [64]. Regarding the role of IL-23 in allergic airway inflammation, a previous study has reported that IL-23 level is increased in the lung upon OVA challenge in a murine model of asthma [58]. In cells from mediastinal lymph nodes of OVA-sensitized and -challenged mice, IL-23 is able to induce IL-17 production, indicating a significant contribution of IL-23 to IL-17 induction in OVA-induced asthma. The production of IL-17 after challenge of LPScontaminated allergens is blunted in IL-6 knockout mice, suggesting that IL- 6 production by LPS is critical for the development of allergen-specific Th17 polarization [61]. Krishnamoorthy et al have demonstrated a central role of c-Kit expressed by dendritic cells in the fine-tuning of the IL-6 expression, which promotes both Th17 and Th2 responses upon stimulation of HDM [59]. The other study has shown that the Toll/IL-1 receptor adaptor pro- 
tein, MyD88 is responsible for the development of Th17mediated allergic airway inflammation in response to HDM [60]. These observations have suggested that allergen-induced IL-17 responses in asthma are regulated via a complex network involving several molecules and various cell types.

A specific role of IL-17 in asthma becomes a matter of primary scientific concern. Supporting the observations in asthmatic patients regarding the role of IL-17 in neutrophilic inflammation, intratracheal administration of IL-17 increases the absolute number of neutrophils in BAL fluids of rat [63]. IL-17 per se, however, does not cause chemotaxis of human neutrophils from peripheral blood, when studied in vitro [64]. In contrast, IL-17 enhances the production of IL-8 in human airway smooth muscle cells, bronchial epithelial cells, and bronchial fibroblast, and the neutrophil chemotactic effect of IL-17 is blocked by an anti-IL-8 antibody (Ab) in vitro $[16,64]$. These data indicate that IL-17 exerts the accumulation of neutrophils into the airways in an indirect manner, mainly via the enhanced production of IL-8, a potent neutrophilic chemoattractant by lung structural cells $[64,65]$. Consistent with previous in vitro studies, our recent study with a murine model of asthma has shown that inhibition of IL-17 activity with an anti-IL-17 Ab remarkably reduces the increase in airway infiltration of neutrophils and expression of $\mathrm{KC}$ (a functional murine homolog of IL-8) protein and mRNA induced by allergen inhalation [66]. Moreover, IL-17 augments the release of IL-6 from human bronchial fibroblasts and expression of G-CSF in bronchial epithelial cells, inducing neutrophil development and granulopoiesis [16,33]. Thus, IL-17 in asthma orchestrates neutrophilic airway inflammation by inducing the release of neutrophilic chemoattractants and activating factors from local cells in the lungs.

While the contribution of IL-17 to neutrophilic asthma has been consistently reported, the direct regulatory effect and mechanism of IL-17 on eosinophilic airway inflammation are somewhat complex to decipher. Interestingly, Schnyder-Candrian et al have reported that IL17 receptor gene-deficient mice show a reduced recruitment of neutrophils as well as eosinophils into the airway after antigen challenge [58]. Furthermore, activity of eosinophil peroxidase in lung tissues and serum concentrations of OVA-specific serum IgE are also reduced in the IL-17 receptor deficient mice [58]. In addition, an involvement of IL-17 in the activation of allergen-specific $\mathrm{T}$ cells has been demonstrated using IL-17-deficient mice [67]. Wakashin and colleagues have reported that adoptive transfer of antigen-specific Th17 cells to mice significantly enhances antigen-induced, Th2 cell-mediated recruitment of eosinophils into the airways and AHR [8]. Supporting the role of IL-17 in Th2 cell-mediated and eosinophilic inflammation in asthma, our recent study has shown that inhibition of IL-17 activity with anti-IL-17 Ab reduces remarkably allergen-induced airway infiltration of inflammatory cells including eosinophils, Th2 cytokine levels in BAL fluids, and AHR [68]. On the other hand, other study has reported that neutralization of IL17 augments the allergic responses in sensitized mice and that intranasal co-administration of OVA with IL-17 reduces pulmonary eosinophil recruitment and AHR, proposing a novel regulatory role of IL-17 [58]. IL-17 seems to decrease CCL11 expression and reduce thymusand activation-regulated chemokine/CCL17 (TARC) production in dendritic cells upon antigen restimulation. These results have suggested that IL-17 has a dual role in the regulation of eosinophilic airway inflammation in asthma. Thus, IL-17 promotes eosinophilic airway inflammation by mounting Th2 responses during antigen sensitization while inhibiting eosinophilic airway inflammation by acting as a down-regulator of the dendritic cell-derived Th2 chemoattractant TARC during the effector phase $[8,58]$. However, more recent studies have reported that administration of anti-IL-17 Ab to OVAinhaled mice in the challenge phase reduces antigeninduced airway infiltration of eosinophils and Th2 cytokine levels in BAL fluids by using different sensitization and challenge protocols $[13,68]$. In addition, an enhancing effect of IL-17 on CCL11 mRNA expression and protein release in human airway smooth muscle cells has been reported $[47,69]$. Moreover, IL-17 activates NF$\kappa \mathrm{B}$ pathway $[38,39]$ that can subsequently induce CCL11 and TARC expression, suspecting the presence of an indirect regulatory pathway $[47,70]$. These observations suggest that IL-17 is associated with Th2 cell-mediated eosinophilic inflammation in asthma, although a few controversial issues and the direct regulatory mechanism remain to be clarified. The discrepancy in the results obtained from various animal models can be explained by different experimental conditions, such as protocols and routes of sensitization and challenge, types of antigens, and mouse strain. This variability may be relevant to humans. Furthermore, asthma is a complex, heterogeneous disease that cannot be explained by one underlying mechanism [71]. Therefore, the mode or level of IL-17's contribution to allergic inflammation may be different depending on asthma endotypes. Taken together, even though more studies are required to determine the primary role and downstream signaling mechanism of IL17, IL-17 seems to contribute to neutrophilic inflammation as well as Th2 cell-mediated and eosinophilic inflammation in asthma.

Mucus hypersecretion and persistent airway inflammation are common features of asthma. Chen et al have found that IL-17 stimulates the expression of mucin genes, MUC5B and MUC5AC, in the airway epithelial cells and that its effect on MUC5B expression is at least 
partly mediated by IL-6 in a JAK2-dependent pathway [72]. As the contribution of excessive airway mucus to asthma pathology is clear, the increase in mucus production can be an action mechanism of IL-17 in asthma. The potential significance of Th17 responses in asthma stems partly from the effects of Th17 cells on the function of regulatory $\mathrm{T}$ cells controlling effector $\mathrm{T}$ cell responses [73]. Thus, the inhibition of IL-17 can be a way to control inflammation but also to restore regulatory $\mathrm{T}$ cell functions in asthma [74]. In short, accumulating evidence indicates that IL-17 is implicated to the pathogenesis of asthma, suggesting IL-17 as an attractive therapeutic target for asthma.

\section{3) Limitations of targeting IL-17 in asthma}

Although the information regarding direct involvement of IL-17 in human defense mechanism is still limited, studies using animal models of infection provide evidence for the role of IL-17 in mammalian immune response against pathogens [14]. IL-17 contributes to host defense against respiratory bacteria and fungi through its promoting effects on neutrophil recruitment and activation $[65,75]$. In addition, IL-17 up-regulates several acute phase response proteins and antimicrobial proteins, including serum amyloid A, C-reactive protein, lipocalin $2, \beta$-defensins, and S100 proteins [48,75]. Actually, mice lacking either IL-17 or IL-17RA are susceptible to lung infection with the gram negative bacteria $[65,75]$. STAT3 plays a critical role in Th17 development and thus displays multiple functions in host defense against extracellular pathogens. Recent studies have demonstrated that mutations in STAT3 in animal models and humans confer a defect in IL-17 function and result in high susceptibility to respiratory infections with extracellular bacteria and fungi [75-77]. These findings indicate that blockade of IL-17 may be associated with an increased risk of opportunistic infections. In addition, IL-17 is involved in regulation of tumor immunity [78]. A major function of IL-17 in the tumor microenvironment is to stimulate tumor growth and progression by facilitating angiogenesis [79]. On the other hand, IL-17 may suppress tumor cell growth through promoting an antitumor cytotoxic $\mathrm{T}$ cell response [80]. Therefore, for the development of IL-17-targeting agents to treat human diseases, researchers should keep in mind that inhibition of IL-17 responses bears potential risk for impairing patients' host defense or antitumor activity.

\section{Targeting IL-17 for treatment of asthma}

Various strategies to down-modulate the IL-17 responses by inhibiting upstream or downstream molecules involved in IL-17 signaling and by blocking IL-17 per se as well as by regulating the differentiation and activation of Th17 cells have been applied as a therapeutic approach for many inflammatory diseases [14]. Here, we discuss the up-to-date modalities to inhibit IL-17 responses with therapeutic effects on asthma (Figure 1).

\section{1) Blockade of IL-17 activity de novo}

The blockade of IL-17 activity with anti-IL-17 Ab decreases the numbers of total cells lymphocytes, neutrophils, and eosinophils in BAL fluids increased after antigen challenge as compared with the numbers in allergeninhaled mice administered isotype control monoclonal $\mathrm{Ab}$ [18,71]. Treatment with the anti-IL-17 Ab also reduces the levels of IL-4, IL-5, and IL-13 in BAL fluids and AHR [71]. Inspiringly, the clinical trials evaluating the efficacy, safety, and tolerability of a monoclonal $\mathrm{Ab}$ against IL-17 in treatment-resistant patients with various inflammatory diseases such as Crohn's disease, rheumatoid arthritis, and psoriasis are underway $[28,81]$. Therefore, the favorable data from animal models of allergeninduced airway inflammatory disease can provide us with the rationale for investigating therapeutic effects of antiIL-17 Ab in asthmatic patients.

Other possible targets to inhibit IL-17 action include receptors for IL-17, IL-17RA and IL-17RC. Human bronchial epithelial cells pretreated with anti-IL-17R Ab show a decrease in IL-17 activity [82]. Kuestner and colleagues have produced a soluble form of IL-17RC, which binds to IL-17 and IL-17F with high affinity and thereby inhibits the signaling of these cytokines in fibroblast [36]. In addition, cultured splenocytes from IL-17RA knockout mice, unlike wild-type mice, did not produce IL- 5 or IL-13 by the stimulation with IL-25 which is known to regulate allergen-induced Th2 responses and AHR [83,84]. Furthermore, treatment with a monoclonal IL-17RA Ab completely inhibited IL-25-induced pulmonary inflammation and AHR [84]. Based on these data, the effect of targeting IL-17 receptor in allergen-induced airway inflammation is anticipated.

\section{2) Modulation of cytokines regulating IL-17 production}

As IL-23 is required for full acquisition of pathogenic function of Th17 cells including IL-17 production, blocking IL-23 may be a promising therapeutic approach to reduce IL-17 production $[8,30]$. IL-23 produced by antigen-presenting cells such as macrophages and dendrite cells induces IL-17 production, which then stimulates the recruitment of inflammatory cells into the lung in murine models of asthma $[58,85,86]$. In accordance with these animal studies, a parallel elevation of IL-17 and IL-23 concentrations in allergic asthmatic patients is observed, suggesting that IL-23 functions as an important regulatory cytokine involved in the Th17-induced inflammation of allergic asthma [55]. A recent study has shown that the increased IL-23 expression in the airways in lung-specific IL-23 transgenic mice is associated with antigen-induced Th2 cytokine production, eosinophil accumulation in the airways, goblet cell hyperplasia, and AHR [8]. Moreover, neutralization of IL-23 activity with 


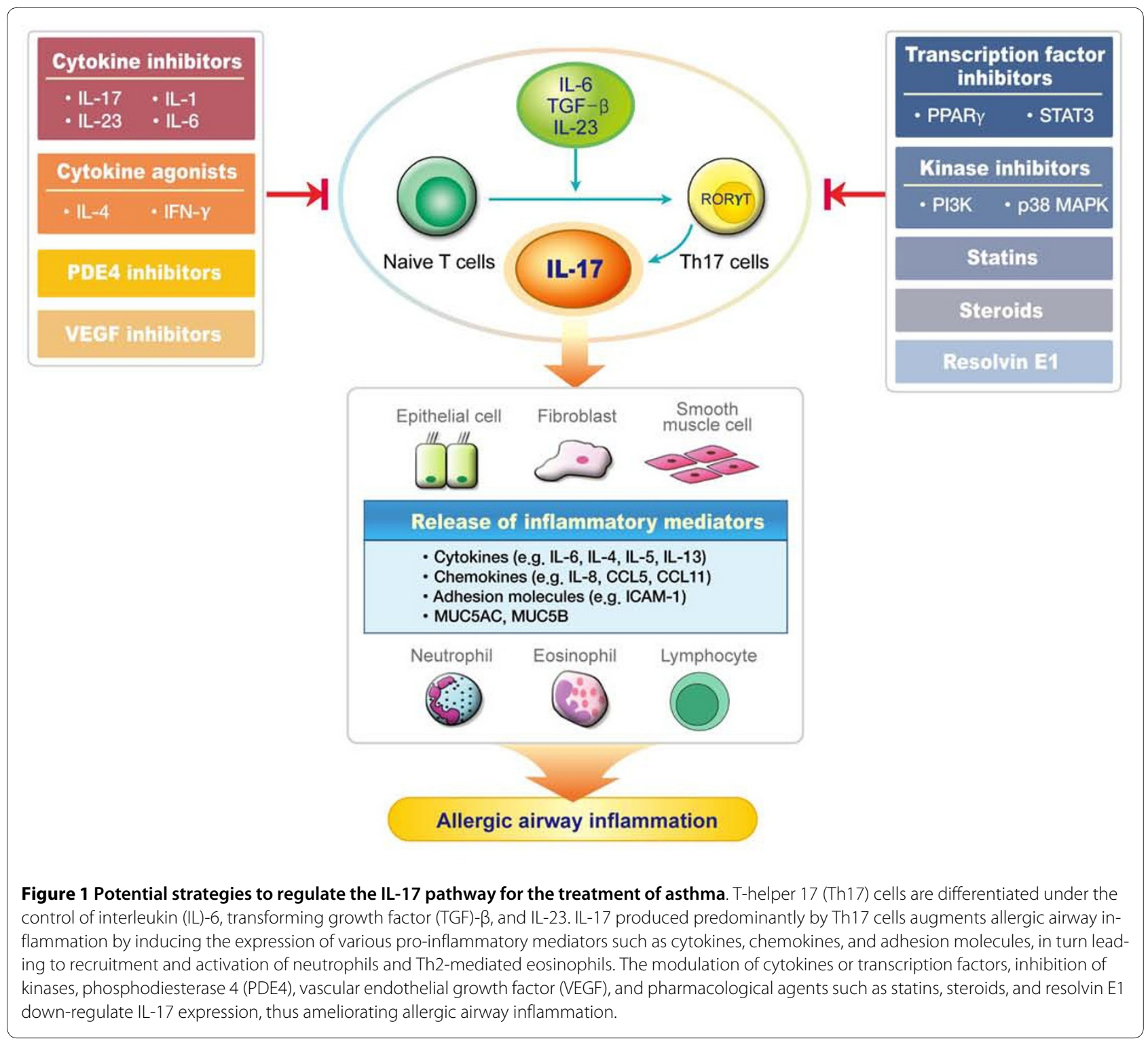

an Ab against IL-23 p19, significantly inhibits the antigen-induced recruitment of lymphocytes, eosinophils, and neutrophils into the airways and decreases the production of Th2 cytokines in the airways of OVA-sensitized mice [8]. These results have provided a possibility that IL-23 inhibition can be a therapeutic strategy reducing IL-17 expression in asthma. For other inflammatory diseases that IL-23 is implicated their pathogenesis, the preclinical and clinical studies with some IL-23 inhibitors have been undertaken [14]. For an example, promising results have been obtained from clinical studies with an oral IL-12/IL-23 inhibitor, STA-5324, in Crohn's disease [87]. Additionally, ustekinumab (CNTO-1275), a subcantaneous monoclonal Ab against the p40 subunit of IL-12 and IL-23 was developed to treat several inflammatory diseases such as psoriasis, psoriatic arthritis, multiple sclerosis, and Crohn's disease [88]. Very recently, a randomised, double-blind, placebo-controlled, crossover trial has shown the efficacy and safety of ustekinumab in treating psoriatic arthritis [89]. The positive results obtained from these clinical studies encourage us to apply to other IL-23/IL-17-related diseases, including asthma.

IL-6 is known as a strong inducer of Th17 cells [26]. Targeting the IL- 6 receptor with a monoclonal Ab was shown to be an effective approach for treating systemiconset juvenile idiopathic arthritis [90]. However, McGeachy et al have reported that IL- 6 with TGF- $\beta$ can drive the production of IL-17 but restrain the pathogenic potential of Th17 cells through up-regulating the production of IL-10, a regulatory cytokine [91]. More recently, a reciprocal role of IL- 6 in generation of Th17 cells and regulatory $\mathrm{T}$ cells in immune response has been proposed 
[92]. IL-6 signaling inhibits the conversion of conventional $\mathrm{T}$ cells into Foxp $3^{+}$regulatory $\mathrm{T}$ cells in vivo [93]. These data have suggested that IL-6 is a potent regulatory factor switching immune responses from the induction of Foxp $3^{+}$regulatory $\mathrm{T}$ cells to pathogenic Th17 cells. Therefore, clarifying the effect of IL-6 in balancing between functions of Th17 cells and regulatory $\mathrm{T}$ cells during allergic responses will make it more clear that blockade of IL- 6 is effective for the inhibition of Th17 cell-mediated inflammation in asthma.

IL-1 plays a pivotal role in developing Th17 cells and eliciting inflammation [94]. IL-1 deficiency or administration of anti-IL-1 receptor type I Ab significantly suppresses the development of arthritis in mice [95]. Interestingly, treatment with a commercially available recombinant IL-1 receptor antagonist (anakinra) results in clinical response in nine patients with systemic onset juvenile idiopathic arthritis that was resistant to conventional aggressive treatment [96]. A previous study has reported that recombinant human IL-1 receptor antagonist effectively suppresses allergen-induced asthmatic symptoms in animal models [97]. However, it is not clear whether the therapeutic effect of the IL-1 receptor antagonist in asthma is due to modulation of Th17 cell development and IL-17 production.

IL-4 and IFN- $\gamma$ negatively regulate the generation and population expansion of IL-17- producing $\mathrm{T}$ cells and their expression of IL-17, which may serve as a protective strategy to fine-tune the expression of IL-17 [5,6]. In OVA-sensitized and -challenged mice, in vivo IFN- $\gamma$ gene delivery through the intravascular injection of plasmid DNA has been shown to suppress airway eosinophilia, IL-5 and IL-13 production, and bronchial mucus production with reducing the production of IL-17 and IFN- $\gamma$ itself in the lung [98]. These results suggest that IFN- $\gamma$ has a broad immune regulatory potential including the suppression of IL-17 production in the lung.

\section{3) Transcription factor inhibitors}

Peroxisome proliferator-activated receptors (PPARs) are members of the nuclear receptor superfamily that regulate gene expression [99]. Among three PPAR subtypes, PPAR $\gamma$ activation down-regulates the synthesis and release of immunomodulatory cytokines from various inflammatory cells [100]. Our recent study has shown that administration of PPARY agonists, rosiglitazone and pioglitazone decreases the IL-17 protein and mRNA expression in the lung and reduces Th2 cytokine expression, AHR, and eosinophil activation, which are increased by induction of asthma [68]. In addition, the attenuating effect of PPAR $\gamma$ agonist on allergic airway inflammation and AHR is abrogated by exogenous IL-17 administration. Accordingly, these results suggest that the therapeutic effect of PPAR $\gamma$ agonist in asthma is exerted by the down-regulation of IL-17 expression, pro- viding a piece of evidence for an interaction between PPAR $\gamma$ signaling and IL-17 expression in allergic airway inflammation.

STAT3 is a transcriptional activator required for IL-17 responses. Saleh et al have shown that IL-17-mediated CC chemokine (CCL11) promoter activity and mRNA expression are decreased in STAT3-silenced airway smooth muscle cells, demonstrating the possible role of IL-17/STAT3 signaling pathway in airway inflammatory responses [69].

\section{4) Kinase inhibitors}

PI3K phosphorylates phosphatidylinositol 4,5-bisphosphate, forming a lipid second messenger, phosphatidylinositol 3,4,5-trisphosphate that controls a variety of intracellular signaling pathways. PI3K is negatively regulated by phosphatase and tensin homolog deleted on chromosome 10 (PTEN). In a murine model of toluene diisocyanate-induced asthma, administration of PI3K inhibitors or gene transfer of PTEN reduces the increase in IL-17 expression in the lung with attenuation of allergen-induced airway inflammation and AHR [13]. In addition, our recent data have revealed that selective inhibition of PI3K $\delta$ isoform remarkably reduces IL-17 expression induced by an allergen challenge [66]. Thus, PI3K/PTEN pathway, especially the PI3K $\delta$ pathway, seems to be a signaling system that regulates IL-17 expression in allergic airway inflammation.

IL-17-induced release of IL- 6 and IL-8 in bronchial epithelial cells is inhibited by the inhibitor of p38 MAPK, SB202190 and by the inhibitor of extracellular signal regulated kinase (ERK), PD98059 in a concentration-dependent manner [101]. The inhibition of p38 MAPK attenuates the release of CXCL1 and CXCL6 induced by IL-17, while blocking the ERK signaling does not display any substantial effect on the release of these chemokines [102]. These observations indicate that p38 MAPK signaling pathway may be the potential pharmacotherapeutical target for the IL-17-mediated airway neutrophilic inflammation.

\section{5) Phosphodiesterase 4 (PDE4) inhibitors}

Selective PDE4 inhibitors, which elevate intracellular cAMP by inhibiting the hydrolysis of cAMP, are effective anti-inflammatory agents in airway inflammatory diseases. A recent study using peripheral blood mononuclear cells and purified $\mathrm{CD}^{+} \mathrm{T}$ cells has demonstrated that treatment of a selective PDE4 inhibitor Zl-n-91 suppresses IL-17 production [103]. Consistent with in vitro results, a selective PDE4 inhibitor, roflumilast decreases the expression of IL-17 mRNA in the airways and suppresses both subepithelial fibrosis and airway epithelial hypertrophy induced by chronic challenge with OVA in mice [104]. These results suggest that PDE4 inhibitors have beneficial effects, at least in part by inhibiting IL-17 
production, in allergen-induced airway inflammation and airway remodeling in asthma.

\section{6) Vascular endothelial growth factor (VEGF) inhibitors}

VEGF, an endothelial cell-specific mitogenic peptide, is a well-known potent promoter of vasculogenesis and angiogenesis. Also, VEGF enhances microvascular permeability, thereby inducing the migration of inflammatory cells to the airway [105]. Therefore, VEGF has been recognized as a crucial stimulator of airway inflammation, AHR, airway remodeling, and Th2 immune responses in asthma. Very recently, the role of VEGF in the polarization to Th17 cells in a murine model of asthma induced by airway sensitization with LPS-contaminated allergens has been evaluated [61]. Treatment with a VEGF receptor inhibitor, SU5416, decreased significantly the levels of IL-17 in BAL fluids after allergen challenge and this effect was accompanied by inhibition of the production of a Th17 polarizing cytokine, IL-6. In addition, the blockade of VEGF signaling by a cyclopeptidic vascular endothelial growth inhibitor, CBO-P11 and a novel VEGF blocker, VEGF-Trap also reduces the IL-17 levels increased after OVA inhalation in a mouse model of asthma (our unpublished data). Therefore, inhibition of VEGF activity is suggested to ameliorate airway inflammation and AHR, regulating the polarization to Th17 cells and the production of IL-17 in asthma.

\section{7) Statins}

Statins are widely used to manage the patients with hyperlipidemia. Interestingly, these cholesterol-lowering agents have been shown to exhibit immunosuppressive effect in several immune-mediated disease models [106]. Simvastatin attenuates release of airway neutrophilic and remodeling mediators and inhibits their up-regulation induced by IL-17 in primary bronchial epithelial cells [107]. Yeh and Huang have reported that treatment of mice with pravastatin reduces airway eosinophilia increased after inhalation of OVA [108]. Moreover, administration of pravastatin suppressed OVA-induced proliferation and production of Th2 cytokines in spleen cells ex vivo and in vitro [108]. In addition, pravastatin suppressed IL-17 production in the thoracic lymph node, eosinophilic airway inflammation, and OVA-specific IgE production in a murine model of asthma [106]. These results indicate that statins down-regulate IL-17 production and thus suppress allergic responses in the airway, suggesting that statins can be a new therapeutic option targeting IL-17 for asthma.

\section{8) Steroids}

Among the current treatments for asthma, steroids are the most commonly used controller as a potent antiinflammatory agent. The IL-17-induced release of IL-8, CXCL1, and CXCL6 from human bronchial epithelial cells might be sensitive to glucocorticoid receptor stimulation [102]. In contrast, another study has reported that dexamethasone fails to attenuate the IL-17-induced release of IL-8 in human airway smooth muscle cells [109]. In animal model of allergic airway inflammation, treatment with dexamethasone significantly decreased mRNA expression of several cytokines including IL-17, which are increased in the airways after chronic challenge with OVA [104]. A recent study has also shown that dexamethasone can inhibit the release of IL-17 by inhibiting RORyt expression and blocking Th17 differentiation in a murine model of OVA-induced asthma [110]. On the contrary, McKinley et al have demonstrated that Th17 cell-mediated airway inflammation and AHR are steroid resistant in mice, suggesting a potential implication of Th17 cells in steroid-resistant asthma [111]. Therefore, whether steroids exert their therapeutic effect through regulating IL-17 production in asthma remains to be evaluated.

\section{9) Resolvin E1}

Epidemiological studies have found that diets rich in omega-3 fatty acids lower the prevalence of asthma [112]. Resolvins are products of omega- 3 fatty acids named on the basis of their original identification in resolving exudates and their ability to exert potent anti-inflammatory properties, accelerating the resolution phase of acute inflammation [113]. In a mouse model of OVA-induced allergic airway inflammation, resolvin E1 promotes the resolution of the inflammatory airway responses in part by directly suppressing the production of IL-23 and IL-6 in the lung [114]. Thus, administration of resolvin E1 decreases concentration of IL-17 protein in BAL fluids and a decreased ratio of IL-17-producing to IFN $\gamma$-producing $\mathrm{T}$ cells [114]. The regulation of adaptive immune responses by resolvin E1 provides a therapeutic strategy via IL-17 regulation for the persistent and unrestrained immune responses of asthma.

\section{Conclusion}

Cytokines play a key role in orchestrating airway inflammation and structural changes of the respiratory tract in asthma, and thus become an important target for the development of therapeutic modalities for the disease. Therefore, the discovery of new cytokine can afford other opportunity to control the inflammatory diseases. Recent studies have provided convincing evidence that IL-17, the predominant product of Th17 cells, plays an imperative role in regulating the expression of inflammatory mediators and the recruitment and function of inflammatory cells in various inflammatory diseases including asthma. As the regulatory systems involved in the differentiation of Th17 cells and the production of IL-17 have been identified, this knowledge has allowed the rationale for the development of novel therapeutic agents targeting IL-17 in asthma. It is very encouraging that the clinical trials on an anti-IL-17 Ab in the patients with IL-17-associated 
inflammatory diseases are underway, although not in asthmatic patients. With regard to asthma, studies using animal models of asthma are on the way, and the data supporting the therapeutic potential of strategies inhibiting IL-17 expression on allergic airway inflammation and AHR are accumulating. In the near future, the question on whether IL-17 is a reliable therapeutic target for asthmatic patients will be answered, hopefully.

Competing interests

The authors declare that they have no competing interests.

\section{Authors' contributions}

SJP and YCL contributed to conception and design and drafted the manuscript. All authors read and approved the final manuscript.

\section{Acknowledgements}

We thank Professor Mie-Jae Im for critical reading of the manuscript. This study was supported by a grant of the Korea Healthcare technology R\&D Project, Ministry for Health, Welfare and Family Affairs, Republic of Korea (A084144).

\section{Author Details}

Department of Internal Medicine and Research Center for Pulmonary Disorders, Chonbuk National University Medical School, Jeonju, South Korea

Received: 20 January 2010 Accepted: 16 June 2010

Published: 16 June 2010

\section{References}

1. Holgate ST: Novel targets of therapy in asthma. Curr Opin Pulm Med 2009, 15:63-71.

2. Adcock IM, Caramori G, Chung KF: New targets for drug development in asthma. Lancet 2008, 372:1073-1087.

3. Holgate ST, Polosa R: Treatment strategies for allergy and asthma. Nat Rev Immunol 2008, 8:218-230.

4. Afshar R, Medoff BD, Luster AD: Allergic asthma: a tale of many T cells. Clin Exp Allergy 2008, 38:1847-1857.

5. Harrington LE, Hatton RD, Mangan PR, Turner H, Murphy TL, Murphy KM, Weaver CT: Interleukin 17-producing CD4+ effector T cells develop via a lineage distinct from the Thelper type 1 and 2 lineages. Nat Immunol 2005, 6:1123-1132.

6. Park H, Li Z, Yang XO, Chang SH, Nurieva R, Wang YH, Wang Y, Hood L, Zhu $Z$, Tian Q, Dong C: A distinct lineage of CD4 T cells regulates tissue inflammation by producing interleukin 17 . Nat Immunol 2005 , 6:1133-1141.

7. Harrington LE, Mangan PR, Weaver CT: Expanding the effector CD4 T-cell repertoire: the Th17 lineage. Curr Opin Immunol 2006, 18:349-356.

8. Wakashin H, Hirose K, Maezawa Y, Kagami S, Suto A, Watanabe N, Saito Y, Hatano M, Tokuhisa T, Iwakura Y, Puccetti P, Iwamoto I, Nakajima H: IL-23 and Th17 cells enhance Th2-cell-mediated eosinophilic airway inflammation in mice. Am J Respir Crit Care Med 2008, 178:1023-1032.

9. Wilson RH, Whitehead GS, Nakano H, Free ME, Kolls JK, Cook DN: Allergic sensitization through the airway primes Th17-dependent neutrophilia and airway hyperresponsiveness. Am J Respir Crit Care Med 2009, 180:720-730.

10. Pappu BP, Angkasekwinai P, Dong C: Regulatory mechanisms of helper T cell differentiation: new lessons learned from interleukin 17 family cytokines. Pharmacol Ther 2008, 117:374-384.

11. Witowski J, Ksiazek K, Jörres A: Interleukin-17: a mediator of inflammatory responses. Cell Mol Life Sci 2004, 61:567-579.

12. Kawaguchi M, Kokubu F, Kuga H, Matsukura S, Hoshino H, leki K, Imai T, Adachi M, Huang SK: Modulation of bronchial epithelial cells by IL-17. J Allergy Clin Immunol 2001, 108:804-809.

13. Kim SR, Lee KS, Park SJ, Min KH, Lee KY, Choe YH, Lee YR, Kim JS, Hong SJ, Lee YC: PTEN down-regulates IL-17 expression in a murine model of toluene diisocyanate-induced airway disease. J /mmuno/ 2007, 179:6820-6829.

14. Ivanov S, Lindén A: Interleukin-17 as a drug target in human disease. Trends Pharmacol Sci 2009, 30:95-103.
15. Fujino S, Andoh A, Bamba S, Ogawa A, Hata K, Araki Y, Bamba T, Fujiyama $Y$ : Increased expression of interleukin 17 in inflammatory bowel disease. Gut 2003, 52:65-70.

16. Molet S, Hamid Q, Davoine F, Nutku E, Taha R, Pagé N, Olivenstein R, Elias J, Chakir J: IL-17 is increased in asthmatic airways and induces human bronchial fibroblasts to produce cytokines. J Allergy Clin Immunol 2001, 108:430-438.

17. Barczyk A, Pierzchala W, Sozanska E: Interleukin-17 in sputum correlates with airway hyperresponsiveness to methacholine. Respir Med 2003, 97:726-733

18. Hellings PW, Kasran A, Liu Z, Vandekerckhove P, Wuyts A, Overbergh L, Mathieu C, Ceuppens JL: Interleukin-17 orchestrates the granulocyte influx into airways after allergen inhalation in a mouse model of allergic asthma. Am J Respir Cell Mol Biol 2003, 28:42-50.

19. Rouvier E, Luciani MF, Mattéi MG, Denizot F, Golstein P: CTLA-8, cloned from an activated $T$ cell, bearing AU-rich messenger RNA instability sequences, and homologous to a herpesvirus saimiri gene. J Immunol 1993, 150:5445-5456.

20. Yao Z, Fanslow WC, Seldin MF, Rousseau AM, Painter SL, Comeau MR, Cohen Jl, Spriggs MK: Herpesvirus Saimiri encodes a new cytokine, IL17 , which binds to a novel cytokine receptor. Immunity 1995, 3:811-821.

21. Yao Z, Timour M, Painter S, Fanslow W, Spriggs M: Complete nucleotide sequence of the mouse CTLA8 gene. Gene 1996, 168:223-225.

22. Gaffen SL: Structure and signalling in the IL-17 receptor family. Nat Rev Immunol 2009, 9:556-567.

23. Kolls JK, Lindén A: Interleukin-17 family members and inflammation. Immunity 2004, 21:467-476.

24. Michel ML, Mendes-da-Cruz D, Keller AC, Lochner M, Schneider E, Dy M, Eberl G, Leite-de-Moraes MC: Critical role of ROR-gammat in a new thymic pathway leading to IL-17-producing invariant NKT cell differentiation. Proc Natl Acad Sci USA 2008, 105:1 9845-19850

25. Lockhart E, Green AM, Flynn JL: IL-17 production is dominated by gammadelta T cells rather than CD4 T cells during Mycobacterium tuberculosis infection. J Immunol 2006, 177:4662-4669.

26. Bettelli E, Korn T, Oukka M, Kuchroo VK: Induction and effector functions of $\mathrm{T}(\mathrm{H}) 17$ cells. Nature 2008, 453:1051-1057.

27. Veldhoen M, Hocking RJ, Atkins CJ, Locksley RM, Stockinger B: TGFbeta in the context of an inflammatory cytokine milieu supports de novo differentiation of IL-17-producing T cells. Immunity 2006, 24:179-189.

28. Miossec P, Korn T, Kuchroo VK: Interleukin-17 and type 17 helper T cells. N Engl J Med 2009, 361:888-898.

29. Nurieva R, Yang XO, Martinez G, Zhang Y, Panopoulos AD, Ma L, Schluns K, Tian Q, Watowich SS, Jetten AM, Dong C: Essential autocrine regulation by IL-21 in the generation of inflammatory T cells. Nature 2007, 448:480-483.

30. Wakashin $\mathrm{H}$, Hirose $\mathrm{K}$, Iwamoto I, Nakajima H: Role of IL-23-Th17 cell axis in allergic airway inflammation. Int Arch Allergy Immunol 2009, 149:108-112.

31. Uhlig HH, McKenzie BS, Hue S, Thompson C, Joyce-Shaikh B, Stepankova R, Robinson N, Buonocore S, Tlaskalova-Hogenova H, Cua DJ, Powrie F: Differential activity of IL-12 and IL-23 in mucosal and systemic innate immune pathology. Immunity 2006, 25:309-318.

32. Wei L, Laurence A, Elias KM, O'Shea JJ: IL-21 is produced by Th17 cells and drives IL-17 production in a STAT3-dependent manner. $\mathrm{J}$ Biol Chem 2007, 282:34605-34610

33. Louten J, Boniface $K$, de Waal Malefyt R: Development and function of TH17 cells in health and disease. JAllergy Clin Immunol 2009, 123:1004-1011.

34. Chung Y, Chang SH, Martinez GJ, Yang XO, Nurieva R, Kang HS, Ma L, Watowich SS, Jetten AM, Tian Q, Dong C: Critical regulation of early Th17 cell differentiation by interleukin-1 signaling. Immunity 2009, 30:576-587.

35. Acosta-Rodriguez EV, Napolitani G, Lanzavecchia A, Sallusto F: Interleukins 1 beta and 6 but not transforming growth factor-beta are essential for the differentiation of interleukin 17-producing human $T$ helper cells. Nat Immuno/ 2007, 8:942-949.

36. Kuestner RE, Taft DW, Haran A, Brandt CS, Brender T, Lum K, Harder B, Okada S, Ostrander CD, Kreindler UL, Aujla SJ, Reardon B, Moore M, Shea P, Schreckhise R, Bukowski TR, Presnell S, Guerra-Lewis P, Parrish-Novak J, Ellsworth JL, Jaspers S, Lewis KE, Appleby M, Kolls JK, Rixon M, West JW 
Gao Z, Levin SD: Identification of the IL-17 receptor related molecule IL17RC as the receptor for IL-17F. J Immunol 2007, 179:5462-5473.

37. Toy D, Kugler D, Wolfson M, Vanden Bos T, Gurgel J, Derry J, Tocker J, Peschon J: Cutting edge: interleukin 17 signals through a heteromeric receptor complex. J Immunol 2006, 177:36-39.

38. Gaffen SL: An overview of IL-17 function and signaling. Cytokine 2008, 43:402-407.

39. Shalom-Barak T, Quach J, Lotz M: Interleukin-17-induced gene expression in articular chondrocytes is associated with activation of mitogen-activated protein kinases and NF-kappaB. J Biol Chem 1998, 27:27467-27473.

40. Schwandner R, Yamaguchi K, Cao Z: Requirement of tumor necrosis factor receptor-associated factor (TRAF) 6 in interleukin 17 signal transduction. J Exp Med 2000, 191:1233-1240.

41. Chang SH, Park H, Dong C: Act1 adaptor protein is an immediate and essential signaling component of interleukin-17 receptor. $\mathrm{J}$ Biol Chem 2006, 281:35603-35607.

42. Qian Y, Liu C, Hartupee J, Altuntas CZ, Gulen MF, Jane-Wit D, Xiao J, Lu Y, Giltiay N, Liu J, Kordula T, Zhang QW, Vallance B, Swaidani S, Aronica M, Tuohy VK, Hamilton T, Li X: The adaptor Act1 is required for interleukin 17-dependent signaling associated with autoimmune and inflammatory disease. Nat Immunol 2007, 8:247-256.

43. Li X: Act1 modulates autoimmunity through its dual functions in CD40L/BAFF and IL-17 signaling. Cytokine 2008, 41:105-113.

44. Huang F, Kao CY, Wachi S, Thai P, Ryu J, Wu R: Requirement for both JAKmediated PI3K signaling and ACT1/TRAF6/TAK1-dependent NFkappaB activation by IL-17A in enhancing cytokine expression in human airway epithelial cells. J Immuno/ 2007, 179:6504-6513.

45. Fossiez F, Djossou O, Chomarat P, Flores-Romo L, Ait-Yahia S, Maat C, Pin JJ, Garrone P, Garcia E, Saeland S, Blanchard D, Gaillard C, Das Mahapatra B, Rouvier E, Golstein P, Banchereau J, Lebecque S: T cell interleukin-17 induces stromal cells to produce proinflammatory and hematopoietic cytokines. J Exp Med 1996, 183:2593-2603.

46. Shen F, Gaffen SL: Structure-function relationships in the IL-17 receptor: implications for signal transduction and therapy. Cytokine 2008, 41:92-104.

47. Rahman MS, Yamasaki A, Yang J, Shan L, Halayko AJ, Gounni AS: IL-17A induces eotaxin-1/CC chemokine ligand 11 expression in human airway smooth muscle cells: role of MAPK (Erk1/2, JNK, and p38) pathways. J Immunol 2006, 177:4064-4071.

48. Kao CY, Huang F, Chen Y, Thai P, Wachi S, Kim C, Tam L, Wu R: Upregulation of $\mathrm{CC}$ chemokine ligand 20 expression in human airway epithelium by IL-17 through a JAK-independent but MEK-NFkappaBdependent signaling pathway. J Immuno/ 2005, 175:6676-6685.

49. Hsu HC, Yang P, Wang J, Wu Q, Myers R, Chen J, Yi J, Guentert T, Tousson A, Stanus AL, Le TV, Lorenz RG, Xu H, Kolls JK, Carter RH, Chaplin DD, Williams RW, Mountz JD: Interleukin 17-producing T helper cells and interleukin 17 orchestrate autoreactive germinal center development in autoimmune BXD2 mice. Nat Immunol 2008, 9:166-175.

50. Wong $\mathrm{CK}$, Ho CY, Ko FW, Chan $\mathrm{CH}$, Ho AS, Hui DS, Lam CW: Proinflammatory cytokines (IL-17, IL-6, IL-18 and IL-12) and Th cytokines (IFN-ץ, IL-4, IL-10 and IL-13) in patients with allergic asthma. Clin Exp Immunol 2001, 125:177-183.

51. Sun YC, Zhou QT, Yao WZ: Sputum interleukin-17 is increased and associated with airway neutrophilia in patients with severe asthma. Chin Med J 2005, 118:953-956.

52. Bullens DM, Truyen E, Coteur L, Dilissen E, Hellings PW, Dupont $L$, Ceuppens JL: IL-17 mRNA in sputum of asthmatic patients: linking T cell driven inflammation and granulocytic influx? Respir Res 2006, 7:135.

53. Hashimoto T, Akiyama K, Kobayashi N, Mori A: Comparison of IL-17 production by helper $T$ cells among atopic and nonatopic asthmatics and control subjects. Int Arch Allergy Immunol 2005, 137:51-54.

54. Chakir J, Shannon J, Molet S, Fukakusa M, Elias J, Laviolette M, Boulet LP, Hamid Q: Airway remodeling-associated mediators in moderate to severe asthma: effect of steroids on TGF-beta, IL-11, IL-17, and type I and type III collagen expression. JAllergy Clin Immunol 2003, 111:1293-1298.

55. Zhao Y, Yang J, Gao YD, Guo W: Th17 Immunity in patients with allergic asthma. Int Arch Allergy Immunol 2009, 151:297-307.

56. Jatakanon A, Uasuf C, Maziak W, Lim S, Chung KF, Barnes PJ: Neutrophilic inflammation in severe persistent asthma. Am J Respir Crit Care Med 1999, 160:1532-1539.
57. He R, Kim HY, Yoon J, Oyoshi MK, MacGinnitie A, Goya S, Freyschmidt EJ, Bryce P, McKenzie AN, Umetsu DT, Oettgen HC, Geha RS: Exaggerated IL17 response to epicutaneous sensitization mediates airway inflammation in the absence of IL-4 and IL-13. J Allergy Clin Immunol 2009, 124:761-770.

58. Schnyder-Candrian S, Togbe D, Couillin I, Mercier I, Brombacher F, Quesniaux V, Fossiez F, Ryffel B, Schnyder B: Interleukin-17 is a negative regulator of established allergic asthma. JExp Med 2006, 203:2715-2725

59. Krishnamoorthy N, Oriss TB, Paglia M, Fei M, Yarlagadda M Vanhaesebroeck B, Ray A, Ray P: Activation of c-Kit in dendritic cells regulates T helper cell differentiation and allergic asthma. Nat Med 2008, 14:565-573.

60. Phipps S, Lam CE, Kaiko GE, Foo SY, Collison A, Mattes J, Barry J, Davidson S, Oreo K, Smith L, Mansell A, Matthaei KI, Foster PS: Toll/IL-1 signaling is critical for house dust mite-specific helper T cell type 2 and type 17 [corrected] responses. Am J Respir Crit Care Med 2009, 179:883-893.

61. Kim YS, Hong SW, Choi JP, Shin TS, Moon HG, Choi EJ, Jeon SG, Oh SY, Gho YS, Zhu Z, Kim YK: Vascular endothelial growth factor is a key mediator in the development of T cell priming and its polarization to type 1 and type 17 T helper cells in the airways. J Immunol 2009, 183:5113-5120.

62. Lindén A, Laan M, Anderson GP: Neutrophils, interleukin-17A and lung disease. Eur Respir J 2005, 25:159-172.

63. Hoshino $H$, Lötvall J, Skoogh BE, Lindén A: Neutrophil recruitment by interleukin-17 into rat airways in vivo. Role of tachykinins. Am J Respir Crit Care Med 1999, 159:1423-1428.

64. Laan M, Cui ZH, Hoshino H, Lötvall J, Sjöstrand M, Gruenert DC, Skoogh BE, Lindén A: Neutrophil recruitment by human IL-17 via C-X-C chemokine release in the airways. JImmunol 1999, 162:2347-2352.

65. Ye P, Rodriguez FH, Kanaly S, Stocking KL, Schurr J, Schwarzenberger $P$, Oliver P, Huang W, Zhang P, Zhang J, Shellito JE, Bagby GJ, Nelson S, Charrier K, Peschon JJ, Kolls JK: Requirement of interleukin 17 receptor signaling for lung $\mathrm{CXC}$ chemokine and granulocyte colony-stimulating factor expression, neutrophil recruitment, and host defense. J Exp Med 2001, 194:519-527.

66. Park SJ, Lee KS, Kim SR, Min KH, Moon H, Lee MH, Chung CR, Han HJ, Puri KD, Lee YC: Phosphoinositide 3-kinase \{delta\} inhibitor suppresses IL-17 expression in a murine asthma model. Eur Respir $J$ 2010. in press

67. Nakae S, Komiyama Y, Nambu A, Sudo K, Iwase M, Homma I, Sekikawa K, Asano M, Iwakura Y: Antigen-specific T cell sensitization is impaired in IL-17-deficient mice, causing suppression of allergic cellular and humoral responses. Immunity 2002, 17:375-387.

68. Park SJ, Lee KS, Kim SR, Min KH, Choe YH, Moon H, Chae HJ, Yoo WH, Lee YC: Peroxisome proliferator-activated receptor gamma agonist downregulates IL-17 expression in a murine model of allergic airway inflammation. J Immuno/ 2009, 183:3259-3267.

69. Saleh A, Shan L, Halayko AJ, Kung S, Gounni AS: Critical role for STAT3 in IL-17A-mediated CCL11 expression in human airway smooth muscle cells. JImmunol 2009, 182:3357-3365.

70. Berin MC, Eckmann L, Broide DH, Kagnoff MF: Regulated production of the Thelper 2-type T-cell chemoattractant TARC by human bronchial epithelial cells in vitro and in human lung xenografts. Am J Respir Cell Mol Biol 2001, 24:382-389.

71. Anderson GP: Endotyping asthma: new insights into key pathogenic mechanisms in a complex, heterogeneous disease. Lancet 2008, 372:1107-1119.

72. Chen Y, Thai P, Zhao YH, Ho YS, DeSouza MM, Wu R: Stimulation of airway mucin gene expression by interleukin (IL)-17 through IL-6 paracrine/autocrine loop. J Biol Chem 2003, 278:17036-17043.

73. Bettelli E, Oukka M, Kuchroo VK: T(H)-17 cells in the circle of immunity and autoimmunity. Nat Immunol 2007, 8:345-350.

74. Miossec P: IL-17 and Th17 cells in human inflammatory diseases. Microbes Infect 2009, 11:625-630.

75. Alcorn JF, Crowe CR, Kolls JK: TH17 cells in asthma and COPD. Annu Rev Physio/ 2010, 72:495-516

76. Minegishi Y, Karasuyama H: Defects in Jak-STAT-mediated cytokine signals cause hyper-lgE syndrome: lessons from a primary immunodeficiency. Int Immunol 2009, 21:105-112.

77. Milner JD, Brenchley JM, Laurence A, Freeman AF, Hill BJ, Elias KM, Kanno Y, Spalding C, Elloumi HZ, Paulson ML, Davis J, Hsu A, Asher Al, O'Shea J, Holland SM, Paul WE, Douek DC: Impaired T(H)17 cell differentiation in 
subjects with autosomal dominant hyper-IgE syndrome. Nature 2008 452:773-776

78. Murugaiyan G, Saha B: Protumor vs antitumor functions of IL-17. $J$ Immunol 2009, 183:4169-4175.

79. Numasaki M, Fukushi J, Ono M, Narula SK, Zavodny PJ, Kudo T, Robbins PD, Tahara H, Lotze MT: Interleukin-17 promotes angiogenesis and tumor growth. Blood 2003, 101:2620-2627.

80. Benchetrit F, Ciree A, Vives V, Warnier G, Gey A, Sautès-Fridman C, Fossiez F, Haicheur N, Fridman WH, Tartour E: Interleukin-17 inhibits tumor cell growth by means of a T-cell-dependent mechanism. Blood 2002, 99:2114-2121

81. Ouyang W, Kolls JK, Zheng Y: The biological functions of T helper 17 cell effector cytokines in inflammation. Immunity 2008, 28:454-467.

82. McAllister F, Henry A, Kreindler JL, Dubin PJ, Ulrich L, Steele C, Finder JD, Pilewski JM, Carreno BM, Goldman SJ, Pirhonen J, Kolls JK: Role of IL-17A IL-17F, and the IL-17 receptor in regulating growth-related oncogenealpha and granulocyte colony-stimulating factor in bronchial epithelium: implications for airway inflammation in cystic fibrosis. $J$ Immunol 2005, 175:404-412.

83. Ballantyne SJ, Barlow JL, Jolin HE, Nath P, Williams AS, Chung KF, Sturton G, Wong SH, McKenzie AN: Blocking IL-25 prevents airway hyperresponsiveness in allergic asthma. J Allergy Clin Immunol 2007 , 120:1324-1331

84. Rickel EA, Siegel LA, Yoon BR, Rottman JB, Kugler DG, Swart DA, Anders PM, Tocker JE, Comeau MR, Budelsky AL: Identification of functional roles for both IL-17RB and IL-17RA in mediating IL-25-induced activities. J Immunol 2008, 181:4299-4310.

85. Ivanov II, MCKenzie BS, Zhou L, Tadokoro CE, Lepelley A, Lafaille JJ, Cua DJ, Littman DR: The orphan nuclear receptor RORt directs the differentiation program of proinflammatory IL-17+ Thelper cells. Cell 2006, 126:1121-1133.

86. Peng J, Yang XO, Chang SH, Yang J, Dong C: IL-23 signaling enhances Th2 polarization and regulates allergic airway inflammation. Cell Res 2010, 20:62-71.

87. Burakoff R, Barish CF, Riff D, Pruitt R, Chey WY, Farraye FA, Shafran I, Katz $S$, Krone CL, Vander Vliet M, Stevens C, Sherman ML, Jacobson E, Bleday R: A phase $1 / 2 \mathrm{~A}$ trial of STA 5326 , an oral interleukin-12/23 inhibitor, in patients with active moderate to severe Crohn's disease. Inflamm Bowel Dis 2006, 12:558-565.

88. Wittig BM: Drug evaluation: CNTO-1275, a mAb against IL-12/IL-23p40 for the potential treatment of inflammatory diseases. Curr Opin Investig Drugs 2007, 8:947-954.

89. Gottlieb A, Menter A, Mendelsohn A, Shen YK, Li S, Guzzo C, Fretzin S, Kunynetz R, Kavanaugh A: Ustekinumab, a human interleukin 12/23 monoclonal antibody, for psoriatic arthritis: randomised, double-blind, placebo-controlled, crossover trial. Lancet 2009, 373:633-640.

90. Yokota S, Miyamae T, Imagawa T, Iwata N, Katakura S, Mori M, Woo P, Nishimoto N, Yoshizaki K, Kishimoto T: Therapeutic efficacy of humanized recombinant anti-interleukin-6 receptor antibody in children with systemic-onset juvenile idiopathic arthritis. Arthritis Rheum 2005, 52:818-825.

91. McGeachy MJ, Bak-Jensen KS, Chen Y, Tato CM, Blumenschein W, McClanahan T, Cua DJ: TGF- $\beta$ and IL- 6 drive the production of IL-17 and IL-10 by $T$ cells and restrain $\mathrm{T}(\mathrm{H})-17$ cell-mediated pathology. Nat Immunol 2007, 8:1390-1397.

92. Awasthi A, Murugaiyan G, Kuchroo VK: Interplay between effector Th17 and regulatory T cells. J Clin Immunol 2008, 28:660-670.

93. Korn T, Mitsdoerffer M, Croxford AL, Awasthi A, Dardalhon VA, Galileos G, Vollmar P, Stritesky GL, Kaplan MH, Waisman A, Kuchroo VK, Oukka M: IL-6 controls Th17 immunity in vivo by inhibiting the conversion of conventional T cells into Foxp3+ regulatory T cells. Proc Natl Acad Sci USA 2008, 105:18460-18465.

94. Iwakura Y, Nakae S, Saijo S, Ishigame H: The roles of IL-17A in inflammatory immune responses and host defense against pathogens. Immunol Rev 2008, 226:57-79.

95. Probert L, Plows D, Kontogeorgos G, Kollias G: The type I interleukin-1 receptor acts in series with tumor necrosis factor (TNF) to induce arthritis in TNF-transgenic mice. Eur I Immunol 1995, 25:1794-1797.

96. Pascual V, Allantaz F, Arce E, Punaro M, Banchereau J: Role of interleukin1 (IL-1) in the pathogenesis of systemic onset juvenile idiopathic arthritis and clinical response to IL-1 blockade. J Exp Med 2005, 201:1479-1486
97. Li T, Lu WL, Hong HY, Yao YS, Han P, Li ZK, Wang GL, Cao Y, Liu XR, Wang JC, Zhang X, Zhang Q: Pharmacokinetics and anti-asthmatic potential of non-parenterally administered recombinant human interleukin-1 receptor antagonist in animal models. J Pharmacol Sci 2006, 102:321-330.

98. Nakagome K, Okunishi K, Imamura M, Harada H, Matsumoto T, Tanaka R, Miyazaki J, Yamamoto K, Dohi M: IFN-gamma attenuates antigeninduced overall immune response in the airway as a Th1-type immune regulatory cytokine. J/mmuno/ 2009, 183:209-220.

99. Kota BP, Huang TH, Roufogalis BD: An overview on biological mechanisms of PPARs. Pharmacol Res 2005, 51:85-94.

100. Park SJ, Lee YC: Peroxisome proliferator-activated receptor gamma as a novel therapeutic target in asthma. J Asthma 2008, 45:1-8.

101. Laan M, Lötvall J, Chung KF, Lindén A: IL-17-induced cytokine release in human bronchial epithelial cells in vitro: role of mitogen-activated protein (MAP) kinases. Br J Pharmacol 2001, 133:200-206.

102. Prause $O$, Laan M, Lötvall J, Lindén A: Pharmacological modulation of interleukin-17-induced GCP-2-, GRO-alpha- and interleukin-8 release in human bronchial epithelial cells. Eur J Pharmacol 2003, 462:193-198.

103. Ma R, Yang BY, Wu CY: A selective phosphodiesterase 4 (PDE4) inhibitor ZI-n-91 suppresses IL-17 production by human memory Th17 cells. Int Immunopharmacol 2008, 8:1408-1417.

104. Herbert C, Hettiaratchi A, Webb DC, Thomas PS, Foster PS, Kumar RK: Suppression of cytokine expression by roflumilast and dexamethasone in a model of chronic asthma. Clin Exp Allergy 2008, 38:847-856.

105. Lee KS, Park SJ, Kim SR, Min KH, Lee KY, Choe YH, Hong SH, Lee YR, Kim JS, Hong SJ, Lee YC: Inhibition of VEGF blocks TGF-beta1 production through a PI3K/Akt signalling pathway. Eur Respir J 2008, 31:523-531

106. Imamura M, Okunishi K, Ohtsu H, Nakagome K, Harada H, Tanaka R, Yamamoto K, Dohi M: Pravastatin attenuates allergic airway inflammation by suppressing antigen sensitisation, interleukin 17 production and antigen presentation in the lung. Thorax 2009, 64:44-49.

107. Murphy DM, Forrest IA, Corris PA, Johnson GE, Small T, Jones D, Fisher AJ, Egan JJ, Cawston TE, Ward C, Lordan JL: Simvastatin attenuates release of neutrophilic and remodeling factors from primary bronchial epithelial cells derived from stable lung transplant recipients. Am J Physiol Lung Cell Mol Physiol 2008, 294:L592-L599.

108. Yeh YF, Huang SL: Enhancing effect of dietary cholesterol and inhibitory effect of pravastatin on allergic pulmonary inflammation. J Biomed SCi 2004, 11:599-606

109. Vanaudenaerde BM, Wuyts WA, Geudens N, Dupont LJ, Schoofs K, Smeets S, Van Raemdonck DE, Verleden GM: Macrolides inhibit IL17-induced IL8 and 8-isoprostane release from human airway smooth muscle cells. Am J Transplant 2007, 7:76-82.

110. Hu SM, Luo YL, Lai WY, Chen PF: Effects of dexamethasone on intracellular expression of Th17 cytokine interleukin 17 in asthmatic mice. Nan Fang Yi Ke Da Xue Xue Bao 2009, 29:1 185-1188.

111. McKinley L, Alcorn JF, Peterson A, Dupont RB, Kapadia S, Logar A, Henry A, Irvin CG, Piganelli JD, Ray A, Kolls JK: TH17 cells mediate steroid-resistant airway inflammation and airway hyperresponsiveness in mice. J Immunol 2008, 181:4089-4097.

112. Schwartz J, Weiss ST: The relationship of dietary fish intake to level of pulmonary function in the first National Health and Nutrition Survey (NHANES I). Eur Respir J 1994, 7:1821-1824.

113. Serhan CN: Resolution phase of inflammation: novel endogenous antiinflammatory and proresolving lipid mediators and pathways. Annu Rev Immunol 2007, 25:101-137.

114. Haworth O, Cernadas M, Yang R, Serhan CN, Levy BD: Resolvin E1 regulates interleukin 23 , interferon-gamma and lipoxin A4 to promote the resolution of allergic airway inflammation. Nat Immunol 2008, 9:873-879.

doi: $10.1186 / 1465-9921-11-78$

Cite this article as: Park and Lee, Interleukin-17 regulation: an attractive therapeutic approach for asthma Respiratory Research 2010, 11:78 